\title{
The Effect of Two Aerobic Intensities of Exercise on Free Radicals and Antioxidants Formation
}

\author{
Bassam N. Aziz \\ Department of Anesthesia \\ Mosul Technical Institute
}

\author{
Yasin T. Al-Hajjar \\ College of Sport Education \\ Mosul University
}

Ammar F. Matloob

Department of Chemistry

College of Science

Mosul University

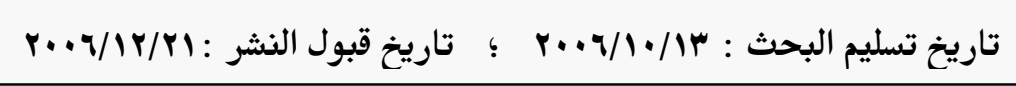

\section{$\underline{\text { ABSTRACT }}$}

This research reviews the role of free radicals in causing oxidative stress during exercise. Low and moderate intensities exercise induce oxidative stress, although there is no evidence that this affects sporting performance in the short term (14 min.). The effects of the two intensities of exercise on the blood antioxidant capacity and serum lipid peroxidation in 7 volunteers male athletes were tested. The results showed significant increased in malondialdehyde (MDA) level (as an index of lipid peroxidation) in subjects after first and second efforts of exercise in comparison with the control group. On the other hand, reduced form of glutathione (GSH) concentration and superoxide dismuatse activity (SOD) were decreased in the exercised experimental subjects under treatment compared to control values. 


\title{
تأثير شدتين هوائيتين على تكوين الجذور الحرة ومضادات الأكسدة
}

\author{
عمار فوزي مطلوب \\ قسم الكيمياء \\ كلية العلوم/ جامعة الموصل
}
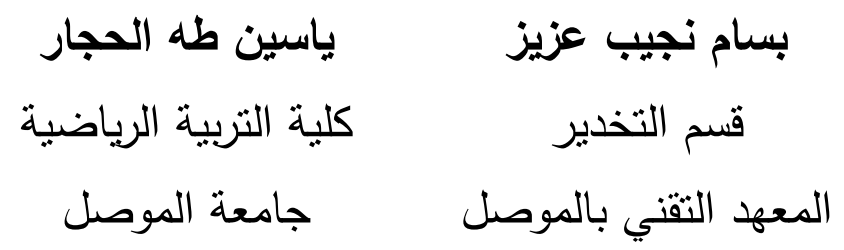

الملخص

يبين هذا البحث دور الجذور الحرة في حدوث الكرب ألتأكسدي خـال التمرين. أحدث

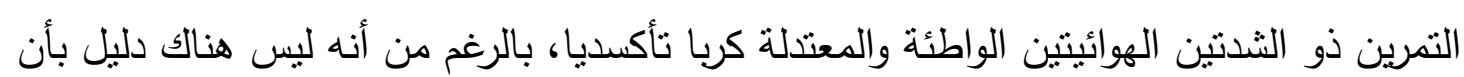
هذا يؤثر في الأداء الرياضي على الددى القريب (ع الهين الوقيقة).

في البحث الحالي تم اختبار تأثثير شدتين للتمرين واطئة ومعتدلة في مستوى مضادات الأكسدة وزناخة الدهن في مصل دم سبعة من الرياضيين المنطوعين. بينت النتائج وجود زيادة

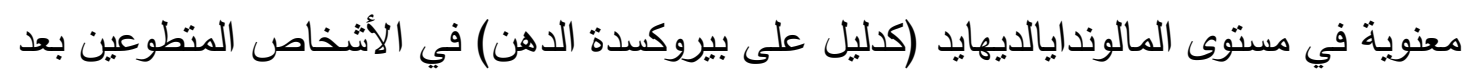

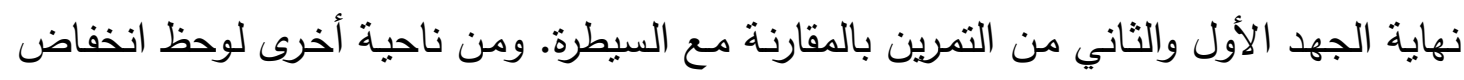
معنوي في نركيز الكلوتاثايون وفعالية أنزيم السوبر أوكسايد دسميوتيز في المعاملات الاختبارية الإنية المعرضة للتمرين بالمقارنة مع قيم السيطرة.

\section{INTRODUCTION}

It was demonstrated for the first time that physical exercise can lead to an increase in lipid peroxidation and free radical production leading to oxidative stress (Dillard et al.,1978). Moreover, in exercise, body needs more oxygen for energy 10 to 20 times more than in resting. This greatly increases the production of free radicals. http://www.thaiwave.com/networkantioxidants/antioxidantenzymes.htm).

Free radicals are chemical species containing one or more unpaired electrons produced in all living cells. Reactive oxygen species (ROS) generation, including free radicals, increases under aerobic endurance stress. The major source of ROS is thought to be the mitochondria of active muscle (Ji, 1999). Under normal physiological conditions, $90 \%$ of the oxygen consumption by body is reduced to water in the mitochonderia (Ames et al., 1995). An elevated metabolic rate as a result of exercise can dramatically increase oxygen consumption in the locomotive muscles (Ji, 1999). Consequently, moderate to high intensity 
aerobic-type exercise produces oxygen free radicals that can cause damage to lipid membranes, proteins, deoxyribonucleic acid (DNA) and other cellular components (Lovlin et al., 1987; Dragon et al., 1991; and Kanter et al., 1993). The damage to lipid membranes, otherwise known as lipid peroxidation is defined as the oxidative deterioration of polyunsaturated fats in cellular lipid membranes caused by oxygen free radicals. Thus, strenuous exercise may manifest an imbalance between ROS and antioxidant defense resulting in an oxidatively stressful environment in the body causing disturbance of intracellular pro-oxidant - antioxidant (Ji, 1999).

Higher organisms have developed a remarkably efficient antioxidant system over the coarse of evolution (Halliwell and Gutteridge, 1989). The extent of oxidative damage during physical exercise is determined not only by the level of free radical generation, but also by the defense capacity of antioxidants (Viitala et al., 2004). In recently years, a general awareness has developed of the importance of antioxidants in the diseased state. However, still insufficient knowledge about the interaction of each antioxidant and exercise, which is important in assessing the adequacy of protection against oxidative damage (Ji, 1999). On this basis, the aim of the present study was performed to evaluate the effects of exercise, as an oxidative stress factor on the oxidant-antioxidant balance.

\section{SUBJECTS AND METHODS \\ Subjects and Exercise Programme:}

Seven male student volunteers athletes in sport education collegeuniversity of Mosul, were recruited to participate in the study. Their heights, weights, ages and pulse rate were $171.3 \pm 3.35 \mathrm{~m}$., $69.0 \pm 7.66 \mathrm{~kg} ., \quad 23.3 \pm 2.56 \mathrm{yr}$ and $76.4 \pm 6.22$ (means $\pm \mathrm{SD}$ ), respectively. All subjects were non-smokers, and had no history of medical disorders. None of the subjects consumed antioxidant supplements during or in the month before the experimental procedures. All tests took place in human performance laboratory between March and April in university of Mosul. The temperature ranged from $17^{\circ} \mathrm{C}$ to $22^{\circ} \mathrm{C}$. Athletes performed all testing in the same equipment conditions and drank the same energy beverage.

Athletes performed a continuous, running test on a motorized treadmill (Cateye Treadmill, model EC-T220, Kuwazu, Higashi sumiyoshi-Ku, OSAKA, JAPAN) for $15 \mathrm{~min}$. at a speed of $7 \mathrm{~km} / \mathrm{hr}$ and $14 \mathrm{~km} / \mathrm{hr}$ for the first and second treatment respectively. The time between the two treatments was one weak. Before the tests were performed, subjects began with a warm-up at $4 \mathrm{~km} /$ hour for five minutes; followed by a period of recovery for another five minutes. At the end of 
the test, the subject was sitting down on the chair and the pulse rate was recorded.

The pulse rate during the speed of $7 \mathrm{~km} / \mathrm{hr}$. and $14 \mathrm{~km} / \mathrm{hr}$ are 111 and $134 \mathrm{beat} / \mathrm{min}$. respectively and that represents 55.6 and 68.3 percentage of the maximum pulse rate respectively. The maximum pulse rate was calculated using the following formula: Maximum pulse rate $=220-$ Age (Cateye Treadmill Catalogue).

\section{Blood Sampling Procedures}

Blood samples (4 ml.) were collected by puncture from an antecubital vein in resting and post-exercise conditions The blood samples were centrifuged ( $4000 \mathrm{rpm}, 4^{\circ} \mathrm{C}, 10$ minutes), and serum was divided into aliquots and frozen in dry ice prior to storage at $-20^{\circ} \mathrm{C}$ until assayed for glutathione, MDA, and superoxide dismutase.

\section{Biological Analyses}

The principal difficulty in trying to study free-radical events in biological systems is the fleetingly short life times of free radicals and even of some reactive species. The problem was not the inability to detect $\mathrm{H}_{2} \mathrm{O}_{2}$, but the failure to realize how rapidly it was degraded in biological systems. It is essential to keep that point in mind when designing research related to oxidative stress (Jenkins, 2000).

\section{Determination of Reduced Glutathione(GSH) in Blood Serum}

Reduced glutathione was determined in blood serum using a modified method dependant by Sedlack and Lindsay, (1968). The method depends on Ellman's reagent which contains [5,5-dithiobis(2nitrobenzoic acid)] or known as DTNB which reacts with the thiol group of reduced glutathione to form a coloured solution absorbed at (412) nm.

\section{Determination of Lipid Peroxidation in Blood Serum (Malondialdehyde,} MDA)

Lipid peroxidation level was determined in blood serum through the measurement of MDA concentration. The method depends on the reaction between MDA and thiobarbituric acid or (Beruge and Aust, 1978) to form a coloured solution absorbed at (532)nm.

\section{Determination of Superoxide Dismutase (SOD) Activity in Blood Serum}

Superoxide dismutase (SOD) activity in blood serum was determined using photochemical method. The method included using sodium cyanide as peroxidase inhibitor. This methods depends on an indirect approach to determine the SOD activity through the change in formazene absorbance formed from the reduction of $\mathrm{O}_{2}{ }^{*}$ (which is 
produced by radiating the sample of serum with light) for nitroblue tetrazolum (NBT) dye (Brown and Goldstein, 1983). Decreased difference in formazene absorbance means increased SOD activity.

\section{Data Analysis}

All values are presented as means $\pm \mathrm{SD}$. Between-group, differences for selected variables were determined by paired Student's $t$-tests.

\section{RESULTS}

Reduced glutathione, MDA, and superoxide dismutase activity in blood serum in response to exercise are listed in Table 1.

Running test on a motorized treadmill $(7 \mathrm{~km} / \mathrm{hr}$.) produced a significant decrease in reduced glutathione (GSH) when compared with the control value $(\mathrm{p}<0.01)$. Moreover, increased exercise intensity to (14 $\mathrm{km} / \mathrm{hr}$.) produced a significant decrease in (GSH) in comparison with the control and low intensity exercised treatment $(\mathrm{p}<0.01)$.

Table 1: Effect of two exercise intensities on glutathione and malondialdehyde concentration and superoxide dismutase activity.

\begin{tabular}{|c|c|c|c|}
\hline Parameters & $\begin{array}{c}\text { Control Values } \\
(\mathbf{n}=\mathbf{7})\end{array}$ & $\begin{array}{l}\text { Treatment I } \\
\qquad(\mathbf{n}=7)\end{array}$ & $\begin{array}{c}\text { Treatment II } \\
(\mathbf{n}=7)\end{array}$ \\
\hline $\begin{array}{l}\text { Malondialdehyde } \\
\text { (MDA) } \mu \mathrm{mol} / \mathrm{L}\end{array}$ & $0.18 \pm 0.11$ & $0.29 \pm 0.02 * * *$ & $0.41 \pm 0.03 * * * x \times x$ \\
\hline $\begin{array}{c}\text { Superoxide dismutase } \\
\text { (SOD) }\end{array}$ & $(6.17 \pm 1.8) \times 10^{3}$ & $(6.20 \pm 1.8) \times 10^{3}$ & $\left(6.79 \pm \underset{x x x}{2.1) \times 10} 1^{3 * * *}\right.$ \\
\hline $\begin{array}{l}\text { Glutathione } \\
(\mathrm{GSH}) \mu \mathrm{mol} / \mathrm{L}\end{array}$ & $5.92 \pm 0.12$ & $5.15 \pm 0.12 * * *$ & $4.19 \pm 0.24 * * * x x x$ \\
\hline
\end{tabular}

Treatment I : Represents volunteers running on a treadmill at a speed of $7 \mathrm{~km} / \mathrm{hr}$.

Treatment II: Represents volunteers running on a treadmill at a speed of $14 \mathrm{~km} / \mathrm{hr}$.

Values are mean $\pm \mathrm{SD}$

Statistical differences from control values $* * * \mathrm{p}<0.001$

Statistical differences from Treatment I values ${ }^{\mathrm{xxx}} \mathrm{p}<0.001$

SOD activity expressed by the difference in formazene absorbance before and after irradiation. (Increased absorbance means decreased SOD activity).

Another antioxidant parameter involves superoxide dismutase. Similar to behavior of GSH, serum level of SOD showed a pronounced decrease with a moderate exercise intensity when compared with a low exercised and the control values $(\mathrm{p}<0.01)$. Although there was no significant difference noticed in low exercised intensity $(\mathrm{p}<0.01)$ as compared with the control values.

On the other hand, exercise with low intensity $(7 \mathrm{~km} / \mathrm{hr}$.) caused a significant increase in lipid peroxidation by-product, MDA as compared with the control $(p<0.01)$. Furthermore, during training on treadmill at velocity of $(14 \mathrm{~km} / \mathrm{hr})$, MDA was significantly increased in comparison with the control and low intensity exercised treatments $(\mathrm{p}<0.01)$. 


\section{DISCESSION}

Exercise-induced oxidative stress is a measure of how efficiently and cleanly the mitochondria produce energy. The extent to which cells are stressed following exercise is an indication of cellular health, which is the body's best defense against the effects of aging. To measure oxidative stress, the study evaluated 3 different biomarkers for cellular health and oxidative stress: malondialdehyde and antioxidants like glutathione and superoxide dismutase (Cooper et al. 2002).

Malondialdehyde (MDA) is one of the most frequently used indicators or biomarkers of lipid peroxidation (Nielsen et al., 1997). It was significantly increased as a result of exercise in the present study. Two theories support the concept that resistance exercise could lead to an increase in the production of oxygen free radicals in active muscle sites. A widely held hypothesis involves the ischemia-reperfusion injury (McBride et al., 1997). Intense muscle contractions can result in a temporary decrease in blood flow and oxygen availability and subsequent ischemia. The following reperfusion period (muscle relaxation) produces an abundant reintroduction of $\mathrm{O}_{2}$ and results in the formation of the $\mathrm{O}_{2}{ }^{-}$ radical. Mechanical stress is another hypothesis used to explain an increase in free radicals. In particular, eccentric exercise causes high levels of force that has been shown to initiate muscle tissue damage. This initiates the inflammation process that eventually produces oxygen free radicals (Rokitzki et al., 1994) and lipid peroxidation. Further research is required to support these hypotheses.

The significant increase in MDA agrees with other investigators (Kelle et al., 1999) They reported that moderate intensive treadmill running exercise was sufficient to result in muscle damage and increases in the susceptibility of erythrocytes to in vitro peroxidation represented by MDA. Similar result was reported by others (Rodriguez et al., 2003) where they suggested an increase in plasma MDA immediately after exercise. It was also recorded a significant increase in MDA at 6 hours post exercise

(Viitala et al., 2004).

Lipid peroxidation injury caused by ROS production, as determined by the serum concentration of malondialdehyde in the present study was measured immediately after exercise because ROS production has been shown to decrease rapidly within the first 1-2 min. after muscle contraction ceases (O'Neill et al., 1996).

Apart from the circulating products of free radical reactions, the activity of serum free radical scavengers, known as antioxidants was measured in the present investigations, as well. Antioxidant enzymes may be activated selectively during an acute bout of strenuous exercise depending on the oxidative stress imposed on the specific tissues as well 
as the intrinsic antioxidant defense capacity. Skeletal muscle may be subjected to a greater level of oxidative stress during exercise than liver and heart due to increased ROS production. Therefore, the muscle needs greater antioxidant protection against potential oxidative damage occurring during and/or after exercise.

In biological tissues, the superoxide anion can be converted into the nonradical species hydrogen peroxide and singlet oxygen by the aid of SOD enzyme. Thus, SOD provide the primary defense against ROS generated during exercise. The activity of this enzyme is known to increase in response to exercise in both animal and human studies (Sen, 1995). Unlike to the present study in which SOD activity was decreased significantly $(\mathrm{p}<0.001)$ in training athletes running on a motorized treadmill at a velocity of $15 \mathrm{~km} /$ hour.

On the other hand, exercise with low intensity $(7 \mathrm{~km} / \mathrm{hr}$.) showed no significant changes in SOD activity in subjects when compared with the control group. This could be due to a number of reasons. First, the use of different factors such as training status. Secondly, a wide range of different exercise protocols has been used. Only high intensity, or long duration, exercise appears to lead to a large enough increase in free radical production to overwhelm the antioxidant defences (Niess et al. 1996). Some products of oxidative reactions may not be elevated directly after exercise, and reach their maximal levels only hours or even days (Koyama et al. 1999) after the end of exercise. Therefore, the absence of signs of oxidative stress directly after exercise does not necessarily imply that oxidative damage has not occurred.

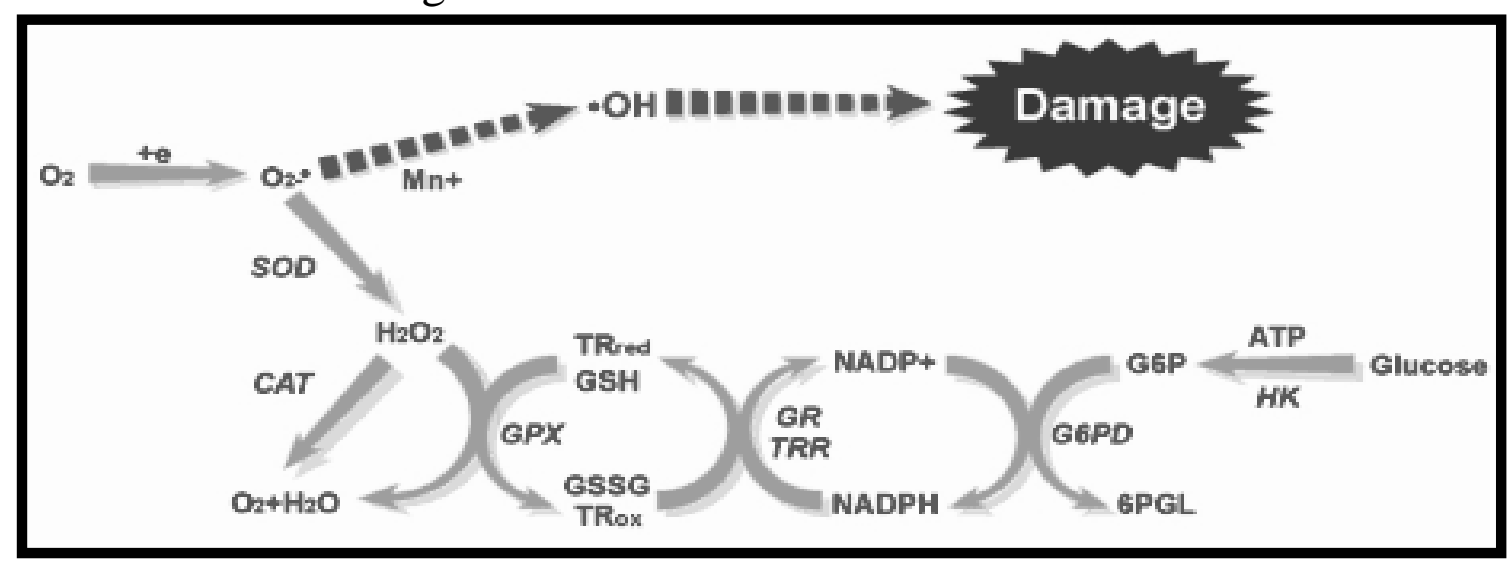

Fig.1: Pathways of reactive oxygen species (ROS) production and clearance. SOD, Superoxide dismutase; CAT, Catalase; GSH, glutathione; GSSG, glutathione disulfide (The free radical theory of aging. http://www.thaiwave.com/networkantioxidants/antioxidantenzymes.htm

GSH ( $\gamma$-glutamylcysteinylglycine) is the most abundant nonprotein thiol source in the cell and serves multiple functions in protecting tissues 
from oxidative damage and keeping the intracellular environment in the reduced state (Meister et. al., 1983). GSH reduces hydrogen- and organicperoxides via a reaction catalyzed by GSH peroxidase (GPX); it serves as a scavenger of $\mathrm{OH}$ and singlet oxygen $\mathrm{O}_{2}{ }^{*}$, thereby preventing free radical chain reaction and lipid peroxidation (Niki et. al., 1985).

GSH was reduced significantly in both groups training on a treadmill in the present study. Similar reports was observed by Kelle et al., (1999) who reports a significant reduction in reduced glutathione (GSH), in Wistar albino rats, whereas oxidized glutathione (GSSG) increased $(\mathrm{p}<0.01$ and $\mathrm{p}<0.001$, respectively).

The antioxidant defences of the body are usually adequate to prevent substantial tissue damage. However, there is not an excess of antioxidant defences, and an overproduction of free radicals or a drop in the level of the antioxidant defences will lead to an imbalance and cause deleterious effects, a situation known as oxidative stress.

There are clear indications that exercise has the potential to increase free radical production and lead to oxidative stress (Packer, 1997).There is an increase in the release of catecholamine hormones during exercise, the auto-oxidation of which can produce free radicals. Muscle damage subsequent to exercise (e.g. in delayed onset muscle soreness) can cause inflammation and release of superoxide from the neutrophil NADPH oxidase. However, it is usually stated that one of the most important source of ROS during exercise is mitochondrial superoxide production, via side-reactions of flavin or ubisemiquinone ( $\mathrm{UQH}^{*}$ ) radicals with oxygen (Ji, 1999). Physical exercise increases energy demand to a large extent, and to provide for this oxygen uptake by the body may increase by as much as 15- fold, and oxygen flux through active muscle may increase by approx. 100-fold above the resting values. Consequently, it is argued that a substantial increase in the production of mitochondrial $\mathrm{O}^{\circ}$ is inevitable. (Cooper et al. 2002).

\section{REFERENCES:}

1. Al-Zamely , O. M., Al-Nimer M. S., Al-Muslih R. K. 2001. Detection the level of peroxynitrite and related with antioxidant status in the serum of pateints with acute myocardial infarction. Nation. J. Chem. 4:625-637.

2. Ames B. N., Shigenaga, M. K., and Hagen, T. M. 1995. Mitochonderial decay in aging. Biochem. Biophys. Acta 1271: 165-170.

3. Beuge, J. A., and Aust, S. D. 1978. "Estiamtion of serum malondialdehyde level". Methods in Enzymology., Academic press, London, 51: 302.

4. Brown, M. S., and Goldstein. 1983. Ann. Rev. Biochem. 52, 223. (cited by Al-Zamely et al., 2001). 
5. Cateye Treadmill Catalogue, Instruction Manual, model EC-T220, Kuwazu, Higashi sumiyoshi-Ku, OSAKA, JAPAN. P: 23.

6. Cooper, C. E., Vollaar, N. B. J., Choueiri, T. and Wilson, M. T. 2002. Exercise, free radicals and oxidative stress. Biochem. Soc. Transactions., 30: 280-285.

7. Dillard, C. J., Litov, R. E., Savin, W. M., Dumelin, E. E. and Tappel, A. L. 1978. J. Appl. Physiol. 45: 927-932 (cited by Cooper et al., 2002)

8. Dragon, I., Dinu, V., Dristea, E., Mohora, N., Ploesteanu, E., and Stroescu, V. 1991. Studies regarding the effects of an antioxidant compound in top athletes. Revue Roumaine de Physiologie. 28:105108.

9. Droge, W. 2002. Free Radicals in the Physiological Control of Cell Function. 82: 47-95.

10.Free radicals and anti-oxidants activate immune system complex http://www.melaleuca.com/wc/pdf/0302USActivate.

11.Halliwell, B., and Gutteridge, J. M. C. 1989. Free radicals in biology and medicine. ( $2^{\text {nd }}$ ed). Oxford: Clarendon Press, pp136-158.

12.Jenkins, R. R. 2000. Exercise and oxidative stress methodology. Am. J. Clin Nutr. 72: 670S-674S

13. Ji L.L. 1999. Antioxidants and oxidative stress in exercise. Proc. Soc. Exp. Biol. Med. 222: 283 -292.

14.Kanter, M.A., Nolte, L.A., and Holloszy, J.O. 1993. Effects of an antioxidant mixture on lipid peroxidation at rest and post exercise. Amer. Physio. Soc. 74:965-969.

15.Kelle, M., Diken, H., Sermet, A., Atmaca, M., and Tümer, C. 1999. Effect of Exercise on Blood Antioxidant Status and Erythrocyte Lipid Peroxidation: Role of Dietary Supplementation of Vitamin E. Tr. J. of Med. Sci. 29: 95-100.

16.Koyama, K., Kaya, M., Ishigaki, T., Tsujita, J., Hori, S., Seino, T. and Kasugai, A. 1999. Eur. J. Appl. Physiol. Occup. Physiol. 80: 28- 33. (cited by Cooper et al., 2002)

17.Lovlin, R., Cottle, W., Pyke, I., Kavanagh, M., and Belcastro, A.N. 1987. Are indices of free radical damage related to exercise intensity. Europ. J. Appl. Physio. 56:313-316. (cited by Viitala et al., 2004)

18.McBride, J.M., Kraemer, W.J., Triplett-McBride T., Sebastianelli, W. 1997. Effect of resistance exercise on free radical production. Medicine and Science in Sports and Exercise. 30:67-72. (cited by Viitala et al., 2004)

19.Meister, A., Anderson, M. E. Glutathione. 1983. Annu. Rev. Biochem. 52: 711-760. (cited by Ji, 1999)

20.Nielsen, F., Mikkelsen, B. B., Nielsen, J. B., Andersen, H. R., and Grandjean, P. 1997 Plasma malondialdehyde as biomarker for oxidative 
stress: reference interval and effects of life-style factors Clinical Chemistry 43: 1209-1214

21.Niess, A. M., Hartmann, A., Grunert-Fuchs, M., Poch, B. and Speit, G. 1996. Int. J. Sports Med. 17: 397- 403. (cited by Cooper et al., 2002)

22.Niki E, Kawakami A, Saito M, Yamamoto Y, Tsuchiya J, Kamiya Y. Effect of phytyl side chain of vitamin $\mathrm{E}$ on its antioxidant activity. $\mathrm{J}$ Biol Chem 260:2191-2196, 1985

23.O'Neill, C. A., Stebbins, C. L., Bonigut, S., Halliwell, B., and Longhurst, J. C. 1996. Production of hydroxyl radicals in contracting skeletal muscle of cats. J. Appl. Physiol. 81: 1197-1206.

24.Packer, L. (1997) J. Sports Sci. 15, 353-363(cited by Cooper et al., 2002)

25.Rodriguez, M.C., Rosenfeld, J., and Tarnopolsky, M. A. 2003. Plasma malondialdehyde increases transiently after ischemic forearm exercise. Med Sci Sports Exerc. 35 (11) :1859-1865.

26.Rokitzki, L., Logemann, E., Huber, G., Keck, E., Keul, J. 1994. $\alpha$ Tocopherol supplementation in racing cyclists during extreme endurance training. Internat. J. Sport Nut. 4:253-264. (cited by Viitala et al., 2004)

27.Sedlak, J., Lindsay, R. H.(1968).Anal. Biochem.192. (cited by AlZamely et al., 2001).

28.Sen, C. K. 1995. Oxidants and antioxidants in exercise. J. Appl. Physiol. 79:675-686.

29.Viitala, P. E., Newhouse, I. J., LaVoie, N., and Gottardo, C. Published online 2004. The effects of antioxidant vitamin supplementation on resistance exercise induced lipid peroxidation in trained and untrained participants. Lipids Health Dis. 3: 14. 